\title{
Metabolic rate, evaporative water loss and thermoregulatory state in four species of bats in the Negev desert
}

\author{
Agustí Muñoz-Garcia a,b,*, Paloma Larraín a , Miriam Ben-Hamo a , Ariovaldo Cruz-Neto ${ }^{\text {c }}$, Joseph B. Williams ${ }^{\text {b }}$, \\ Berry Pinshow ${ }^{a}$, Carmi Korine ${ }^{\mathrm{a}}$ \\ a Mitrani Department of Desert Ecology, Jacob Blaustein Institutes for Desert Research, Ben-Gurion University of the Negev, 8499000 Midreshet Ben-Gurion, Israel \\ ${ }^{b}$ Department of Evolution, Ecology and Organismal Biology, Ohio State University at Mansfield, Aronoff Lab, 318 W 12th Ave., Columbus, OH 43210, United States \\ c Departamento de Zoologia, IB, Universidade Estadual Paulista, Caixa Postal 199, 13506-900 Rio Claro, São Paulo, Brazil
}

\section{A R T I C L E I N F O}

\section{Article history:}

Received 16 June 2015

Received in revised form 7 October 2015

Accepted 7 October 2015

Available online 13 October 2015

\section{Keywords:}

Bats

Respiratory water loss

Cutaneous evaporative water loss

Metabolic rate

Torpor

Desert

\begin{abstract}
A B S T R A C T
Life in deserts is challenging for bats because of their relatively high energy and water requirements; nevertheless bats thrive in desert environments. We postulated that bats from desert environments have lower metabolic rates (MR) and total evaporative water loss (TEWL) than their mesic counterparts. To test this idea, we measured MR and TEWL of four species of bats, which inhabit the Negev desert in Israel, one species mainly restricted to hyper-arid deserts (Otonycteris hemprichii), two species from semi-desert areas (Eptesicus bottae and Plecotus christii), and one widespread species (Pipistrellus kuhlii). We also measured separately, in the same individuals, the two components of TEWL, respiratory water loss (RWL) and cutaneous evaporative water loss (CEWL), using a mask. In all the species, MR and TEWL were significantly reduced during torpor, the latter being a consequence of reductions in both RWL and CEWL. Then, we evaluated whether MR and TEWL in bats differ according to their geographic distributions, and whether those rates change with $T_{\mathrm{a}}$ and the use of torpor. We did not find significant differences in MR among species, but we found that TEWL was lowest in the species restricted to desert habitats, intermediate in the semi-desert dwelling species, and highest in the widespread species, perhaps a consequence of adaptation to life in deserts. Our results were supported by a subsequent analysis of data collected from the literature on rates of TEWL for 35 bat species from desert and mesic habitats.
\end{abstract}

C 2015 Elsevier Inc. All rights reserved.

\section{Introduction}

Mid-latitude deserts are characterized by high daytime ambient temperatures $\left(T_{\mathrm{a}}\right)$, intense solar radiation, low humidity, desiccating winds, scarce and unpredictable food supplies, and free-water availability (Noy-Meir, 1973), conditions that potentially exert strong selective pressures on biota. Some endothermic animals that live in deserts have morphological and behavioral adaptations, which include different degrees of fossoriality, nocturnality, or both, thus avoiding high heat loads and low air humidity during the day (Schmidt-Nielsen, 1964). Desert-dwelling birds and mammals are also physiologically adapted to cope with these environmental conditions; they have generally lower metabolic rates (MR) and lower rates of evaporative water loss (EWL) than their mesic counterparts (Schmidt-Nielsen and Schmidt-Nielsen, 1950; Lovegrove, 2000, 2003; Williams and Tieleman, 2005; Van Sant et al., 2012).

\footnotetext{
* Corresponding author at: Department of Evolution, Ecology and Organismal Biology, Ohio State University, Aronoff Lab, 318 W 12th Ave., Columbus, OH 43210, United States.

E-mail address: munozgarcia.1@osu.edu (A. Muñoz-Garcia).
}

The only order of volant mammals, bats number over 1300 species, which occupy a variety of habitats on all continents, except Antarctica (Fenton and Simmons, 2014). Although bats expend some 15 times as much energy during flight than at rest (Speakman and Thomas, 2003), they have lower basal metabolic rates (BMR) than that of other mammals of the same body mass $\left(m_{\mathrm{b}}\right)$ (McNab, 1982; Speakman and Thomas, 2003; Marom et al., 2006). Bats have significantly larger surface to volume ratios than terrestrial mammals of similar $m_{\mathrm{b}}$ due to their membranous wings, which are vascularized and not insulated by fur (Hill and Smith, 1984), leading to the idea that cutaneous evaporative water loss should be significant in bats (Licht and Leitner, 1967; Thomas et al., 1991; Minnaar et al., 2014)

Total evaporative water loss (TEWL), the sum of respiratory water loss (RWL) and cutaneous evaporative water loss (CEWL), is the main avenue of water loss in small mammals, representing up to $80-85 \%$ of their total water loss (Studier, 1970). Some bats apparently lose twice as much water through evaporation than terrestrial mammals of the same body mass because of their relatively large surface areas (Studier, 1970; Webb, 1995), but these conclusions are based on studies 
with small samples sizes. Therefore, it is intriguing that bats live in many desert environments, since they harbor traits that potentially increase energy consumption and water loss.

Many species of bats can enter torpor, a state wherein bats allow their body temperature $\left(T_{\mathrm{b}}\right)$ to drop below normal by 5 $15^{\circ} \mathrm{C}$, but as much as $20^{\circ} \mathrm{C}$, with a concomitant decrease in MR and possibly water loss (Herreid and Schmidt-Nielsen, 1966; Webb, 1995; Schmidt-Nielsen, 1997; Ruf and Geiser, 2014). Torpor may be a key feature that allows mammals to colonize and survive in a wide variety of habitats (Bozinovic and Marquet, 1991; Lovegrove and Raman, 1998; Rambaldini and Brigham, 2008). Bats may enter shallow torpor on a daily basis, reducing $T_{\mathrm{b}}$ by just a few degrees for several hours, or they may endure longer and deeper torpor bouts that can last from weeks to months. Prolonged bouts of deep torpor are used by species of bats from diverse environments and may occur at low $T_{\mathrm{a}}$, hibernation in winter, for example, or when prey are scarce (Brack and Twente, 1985; Turbill et al., 2003; Geiser, 2004; Zubaid et al., 2006).

Of the 32 species of bats that occur in Israel, 12 species are found in the Negev Desert (Yom-Tov and Kadmon, 1998; Korine and Pinshow, 2004). Consequently it seems likely that these species have adaptations to conserve energy and prevent excessive rates of evaporative water loss (Kunz, 1982; Geiser, 2004; Marom et al., 2006; Muñoz-Garcia et al., 2012a). Nonetheless, some studies report that desert-dwelling bat species do not have significantly lower MR or water loss than those of mesic species (Marom et al., 2006; Muñoz-Garcia et al., 2012a,b), suggesting that desert bats might not show specific adaptations to live in these environments. However, few desert species have been examined. Also, measurements of TEWL available in the literature were mostly made on normothermic animals, i.e., animals defending high $T_{\mathrm{b}}$, with few measurements on torpid bats, making it difficult to evaluate differences in energy expenditure and water fluxes between desert and mesic species.

Since metabolic rates and TEWL are reduced by $50-90 \%$ during torpor (Carpenter, 1969; Morris et al., 1994), the use of torpor by desert species of bats is of adaptive significance. Bats are not known to defecate or urinate during torpor (Webb, 1995), and therefore it is commonly assumed that all water losses during torpor are evaporative. Marom et al. (2006) measured the rates of TEWL in two species of bat that inhabit the Negev Desert: one that lives only in deserts, Otonycteris hemprichii, and another that is found throughout Israel, Tadarida teniotis. Bats entered torpor at low $T_{\mathrm{a}} \mathrm{s}$ during the day, as determined by their significantly reduced $T_{\mathrm{b}}$, compared to $T_{\mathrm{b}}$ in normothermic bats measured at night. The lower MR that ensues during torpor should lead to reduced RWL and, therefore, reduced TEWL. However, the authors did not find significant differences in TEWL between torpid and normothermic bats. These data suggest that during torpor, CEWL might be similar to or even increase over that during normothermy, a counterintuitive result. To test this idea, MuñozGarcia et al. (2012a) measured CEWL and RWL in Kuhl's pipistrelle (Pipistrellus kuhlii) a widespread species but one that also inhabits the Negev Desert. The authors found that, when in deep torpor, CEWL of bats was similar or even higher than that of bats in shallow torpor, leading Muñoz-Garcia et al. (2012a) to hypothesize that bats exert less physiological control over CEWL when torpid.

In the present study, we evaluated whether rates of metabolism and water loss in bats differ according to their geographic distributions, and whether those rates change with $T_{\mathrm{a}}$ and the use of torpor. We measured MR and TEWL of four sympatric species of bats in the Negev Desert: one species whose range is restricted mainly to hyper-arid deserts (O. hemprichii), two hyper-arid and semi-desert species (Eptesicus bottae and Plecotus christii), and one widespread species (P. kuhlii) (Yom-Tov and Kadmon, 1998; Nowak, 1999). We hypothesized that species of bat found only in deserts have adaptations to reduce energy expenditure and water loss, in contrast to bats that live in mesic environments. We predicted that, while euthermic, MR and TEWL of bats at rest would be lowest in the desert species ( 0 . hemprichii), intermediate in the semi-desert dwelling species ( $E$. bottae and $P$. christii), and highest in the widespread species (P. kuhlii). To further test the hypothesis that there is a relationship between TEWL and habitat, we compared rates of TEWL for 35 bat species from desert and mesic habitats. We predicted that desert species have lower rates of TEWL than mesic species. Moreover, we predicted that bats in torpor have reduced MR and rates of TEWL, which result from reductions in both RWL and CEWL, and that these reductions are greater in desert species than in mesic species.

\section{Materials and methods}

\subsection{Experimental animals}

We captured non-reproductive adult bats in the central Negev Highlands. Experiments were done on the Sede-Boqer Campus of BenGurion University of the Negev. Bats were kept in separate, large, covered outdoor cages $(2 \times 2 \times 4 \mathrm{~m})$ and fed daily with sufficient Tenebrio larvae to enable them to maintain $m_{\mathrm{b}}$. Water with vitamins (RIBOS, Biopet, Maabarot, Israel) was provided ad libitum. Bats were exposed to semi-natural weather and light conditions during captivity. The cage was shaded and provided with a bat box for roosting. Once measurements were completed, animals were released at their place of capture.

\subsection{Measurements of resting metabolic rate and total evaporative water loss}

We calculated MR, TEWL, CEWL and RWL in postabsorptive individuals using a multi-channel, open-flow respirometry system to measure $\mathrm{O}_{2}$ consumption $\left(\dot{V} \mathrm{O}_{2}\right), \mathrm{CO}_{2}$ production $\left(\dot{V} \mathrm{CO}_{2}\right)$ and water loss. Measurements were made at four different ambient temperatures $\left(T_{\mathrm{a}}\right)$ : $10{ }^{\circ} \mathrm{C}, 15^{\circ} \mathrm{C}, 30^{\circ} \mathrm{C}$ and $35^{\circ} \mathrm{C}$. Bats were weighed before and after measurements to $\pm 0.01 \mathrm{~g}$ on a digital balance (Scout SP202, Ohaus, NJ, USA). We recorded rectal temperature as a proxy for $T_{\mathrm{b}}$ before and after respirometry measurements using a sheathed, 36-gauge type- $T$ thermocouple, read with a microprocessor thermometer (OMEGA, model HH23, Stanford, CT, USA). We also measured $T_{\mathrm{a}}$ continuously with a thermocouple (same type as above) located inside a controlled temperature cabinet (Thermo Scientific, model Precision 815, OH, USA) where metabolic chambers were placed.

To measure MR and TEWL, we placed each bat in a plastic metabolic chamber (Lock\&Lock model HPL93, 0.35 L). For the smallest species, P. kuhlii, we built chambers using plastic containers $\left(50 \mathrm{~cm}^{3}\right)$ that were covered with dark tape to minimize stress to the animals during measurements. Each chamber was lined with $0.25 \mathrm{~cm}$ plastic-dipped hardware cloth from which the bats could hang upside down. Paraffin oil at the bottom of the chambers trapped feces and urine that could add water vapor to the air sample. Air was pumped into the metabolic chambers from outside the building through a purged gas generator (Purge Gas model \#PCDA-1-12-m-32-C, Broomfield, CO, USA) providing dry, $\mathrm{CO}_{2}$-free air. Flow rates ranged from 160 to $180 \mathrm{~mL} / \mathrm{min}$ for the medium-sized chambers and $\sim 100 \mathrm{~mL} / \mathrm{min}$ for the small chambers. From every chamber, a subsample of air was pumped through an eightchannel multiplexer (G244 gas switcher, Qubit Systems Inc.) that routed the sample of air from each chamber to the gas analyzers, enabling the sequential monitoring of up to six animals. The multiplexer was programmed to automatically select channels, alternating between a chamber containing an animal and the reference channel that had an empty chamber and served to generate a baseline for each cycle. Each cycle started with $300 \mathrm{~s}$ of reference chamber air, followed by $300 \mathrm{~s}$ from each of the chambers containing an animal. We separated the $300 \mathrm{~s}$ intervals with $60 \mathrm{~s}$ switches to the reference chamber. Air coming from the multiplexer was then routed through a dew point meter ( $\mathrm{RH}-$ 
300, Sable Systems International, Inc. Las Vegas, NV, USA), followed by a magnesium perchlorate column to dry the sample, and finally into the $\mathrm{O}_{2}$ and $\mathrm{CO}_{2}$ analyzers (FoxBox $\mathrm{O}_{2}$ and $\mathrm{CO}_{2}$ gas analyzer, Sable Systems International). Each trial lasted 2-4 h, enough time to ensure that bats were at rest when measurements were made. For calculations, we used the average values of $\dot{V} \mathrm{CO}_{2}$ and $\dot{V} \mathrm{O}_{2}$ from traces that remained stable for at least 5 min.

To measure CEWL and RWL, we fitted bats with a mask that covered the snout, following Muñoz-Garcia et al. (2012a). To reduce stress in animals, only one bat was measured at a time at each $T_{\mathrm{a}}$ with this system for a maximum of $2 \mathrm{~h}$ (Muñoz-Garcia et al., 2012a). If the bat removed the mask more than twice, we stopped the measurements and repeated the trial with the same animal another day. The chamber used for these measurements (Lock\&Lock model HPL818, Hana Cobi, Korea, volume $1.56 \mathrm{~L}$ ) had an inlet port and two outlet ports: one for air coming from the chamber and a second for air coming from the mask and the chamber. The flow rate of air entering the chamber was set at $\sim 400 \mathrm{~mL} / \mathrm{min}$. An external pump (Qubit Systems, model P651, Kingston, ON, Canada) regulated the flow rate of the channel used to draw air from the mask, which was set at $\sim 250 \mathrm{~mL} / \mathrm{min}$. This was always higher than the flow rate of the air stream pulled out of the chamber $(\sim 150 \mathrm{~mL} / \mathrm{min})$, to ensure that all respiratory gases were captured in the mask. Measurement cycles started with $300 \mathrm{~s}$ of reference air, followed by $300 \mathrm{~s}$ of air drawn from the outlet port of the chamber, followed by $60 \mathrm{~s}$ of reference air and finishing with $300 \mathrm{~s}$ of air drawn from the outlet port coming from the mask. The bat with its wings folded was immobilized in a horizontal position with small strips of Velcro that were attached to an aluminum mesh frame following Muñoz-Garcia et al. (2012a). Paraffin oil was not used, given the complications of this method. In the event that feces and/or urine were found in the chamber, data were discarded. In each measurement session, we recorded the fractional concentration of $\mathrm{O}_{2}\left(\mathrm{FO}_{2}\right)$ or $\mathrm{CO}_{2}$ $\left(\mathrm{FCO}_{2}\right)$, dew-point temperature, $T_{\mathrm{a}}$ at the dew-point meter, and barometric pressure.

Total evaporative water loss $(\mathrm{g} / \mathrm{h})$ was calculated using the following equation:

$T E W L=\left(V_{\mathrm{e} \rho_{\text {out }}}-V_{\mathrm{i} \rho_{\text {in }}}\right)$

where $V_{\mathrm{i} \rho_{\text {in }}}$ and $V_{\mathrm{e} \rho_{\text {out }}}$ are the incurrent and excurrent flows $(\mathrm{mL} / \mathrm{min})$ times their respective water vapor densities corrected to standard temperature and pressure $\left(\mathrm{g} / \mathrm{m}^{3}, \mathrm{STP}\right)$.

To calculate RWL, we followed Tieleman and Williams (2002):

$R W L=\left(\rho_{\text {mask }}-\rho_{\text {chamber }}\right) \times V_{\mathrm{EM}}$

where $\rho_{\text {mask }}$ is the water vapor density $\left(\mathrm{g} / \mathrm{m}^{3}\right.$, STP) in the sample of air exiting the mask, $\rho_{\text {chamber }}$ is the water vapor density $\left(g / \mathrm{m}^{3}, \mathrm{STP}\right)$ of the air exiting the chamber, and $V_{\mathrm{EM}}$ is the corrected flow rate of air exiting the mask, calculated as:

$\dot{V}_{\mathrm{EM}}=\dot{V}_{\mathrm{IC}}+\dot{V} \mathrm{H}_{2} \mathrm{O}+\dot{V} \mathrm{CO}_{2}-\dot{V} \mathrm{O}_{2}$

where $\dot{V}_{\mathrm{IC}}$ is the flow rate of incurrent air entering the chamber ( $\mathrm{mL} / \mathrm{min}$ ), $\dot{V} \mathrm{H}_{2} \mathrm{O}$ is the volume of water vapor ( $\mathrm{mL} / \mathrm{min}$ ) added by evaporation, $\dot{V} \mathrm{CO}_{2}$ is the volume of $\mathrm{CO}_{2}$ added $(\mathrm{mL} / \mathrm{min}$ ) by the animal and $\dot{V} \mathrm{O}_{2}$ is the volume of $\mathrm{O}_{2}$ it consumed ( $\left.\mathrm{mL} / \mathrm{min}\right)$.

To estimate CEWL, we calculated the water vapor density of the air that left the chamber and the mask and multiplied it by the sum of the flow rates of the air streams coming from the mask and the chamber, as follows:

$C W L=\left(\rho_{\text {chamber }}-\rho_{\mathrm{v} \text {-in }}\right) \times\left(V_{\mathrm{EM}}+V_{\mathrm{EC}}\right)$

where $\rho_{v-\text { in }}$ is the vapor density of the air entering the chamber $\left(\mathrm{g} / \mathrm{m}^{3}\right.$,
STP) and $V_{\mathrm{EC}}$ is the flow rate of the air leaving the chamber. $\dot{V} \mathrm{O}_{2}$ was calculated using equation $4 \mathrm{a}$ of Withers (1977):

$V \mathrm{O}_{2}=\left[V_{\mathrm{E}}\left(F_{\mathrm{I}} \mathrm{O}_{2}-F_{\mathrm{E}} \mathrm{O}_{2}\right)\right] /\left(1-\mathrm{F}_{\mathrm{I}} \mathrm{O}_{2}\right)$

where $\mathrm{F}_{\mathrm{l}} \mathrm{O}_{2}$ is the fraction of $\mathrm{O}_{2}$ entering the mask, and $\mathrm{F}_{\mathrm{E}} \mathrm{O}_{2}$ is the fractional concentration of $\mathrm{O}_{2}$ exiting the mask; therefore, $V_{\mathrm{E}}\left(\mathrm{F}_{\mathrm{I}} \mathrm{O}_{2}-\mathrm{F}_{\mathrm{E}} \mathrm{O}_{2}\right)$ is the difference in the concentration of $\mathrm{O}_{2}$ between inlet and outlet air multiplied by the corrected flow rate (Withers, 1977).

For the calculation of MR of torpid bats, we used $\dot{V} \mathrm{CO}_{2}$, rather than $\dot{V} \mathrm{O}_{2}$ because the signal to noise ration of the $\mathrm{O}_{2}$ analyzer was too low to give accurate readings (Ben-Hamo et al., 2013); $\dot{V} \mathrm{CO}_{2}$ was calculated as follows:

$V \mathrm{CO}_{2}=V_{I}\left[1-\Delta \mathrm{CO}_{2} / 1-(1 / 0.71)\right]$

where $V_{\mathrm{I}}$ is the flow of air incurrent to the chamber and $\Delta \mathrm{CO}_{2}$ is the increase of $\mathrm{CO}_{2}$ produced by the animal in the air sample. We assumed a respiratory exchange ratio of 0.71 for a post-absorptive bat catabolizing only fat (Schmidt-Nielsen, 1997; Muñoz-Garcia et al., 2012a; Ben-Hamo et al., 2013). We used this value to convert $\dot{V} \mathrm{CO}_{2}$ into $\dot{V} \mathrm{O}_{2}$ and then to $\mathrm{mW}$, assuming $19.61 \mathrm{~J}$ is produced for each $\mathrm{mL}$ of $\mathrm{O}_{2}$ consumed (Schmidt-Nielsen, 1997).

\subsection{Data analysis}

All the physiological variables measured in this study are presumably affected by torpor. Many researchers have treated torpor as a categorical variable, either in torpor or not, and determined an arbitrary cutoff of drop in $T_{\mathrm{b}}$ for designating the point at which animals become torpid; others have used the difference between $T_{\mathrm{a}}$ and $T_{\mathrm{b}}$ to classify animals as torpid or normothermic. However, $T_{\mathrm{b}}$ in heterothermic animals is a continuous variable, and individuals experience different depths of torpor depending on environmental conditions, body mass and taxonomic affiliation (see Muñoz-Garcia et al., 2014, and references therein). Therefore, we calculated the thermoregulatory index (TRi), an indicator of the thermoregulatory state of heterothermic endotherms, described by Muñoz-Garcia et al. (2014), as a proxy for depth of torpor. TRi is calculated as:

$T R i=\left[m_{b}\left(T_{b}-T_{a}\right) C_{p}(M R)^{-1}\right] e^{E_{i}[A b s \Delta T] /\left(k \cdot T_{b} \cdot T_{a}\right)}$

where $C_{p}$ is the specific heat capacity of tissues $\left(3.5 \mathrm{~J} / \mathrm{g}{ }^{\circ} \mathrm{C}\right.$ ) (Hart, $1951), E_{i}$ is the energy of activation for biochemical reactions (with an average of $62.72 \mathrm{~kJ} / \mathrm{mol}$ ), $A b s \Delta T$ is the absolute value of the difference between $T_{\mathrm{b}}$ and $T_{\mathrm{a}}$, and $k$ is the Boltzmann constant $\left(1.381 \times 10^{-23} \mathrm{~J} / \mathrm{K}\right)$. TRi can be interpreted as the length of time it takes an animal to generate or dissipate the amount of heat that it will gain or dissipate by physical means (convection, conduction, radiation) to maintain a given temperature gradient with the environment. We used TRi to compare the physiological variables of interest among individuals of different species enduring different depths of torpor.

To test for differences in body temperature $\left(T_{\mathrm{b}}\right)$, we used a mixedeffects ANOVA with bat ID as a random factor nested in species, and with species and ambient temperature $\left(T_{\mathrm{a}}\right)$ as categorical predictors. We used a two-way ANOVA, with $T_{\mathrm{a}}$ and species as fixed factors, to test for significant differences in TRi. To evaluate differences in MR, we used ANCOVA, with $m_{\mathrm{b}}$ as a covariate, and $T_{\mathrm{a}}$ and species as fixed factors. To compare RWL among species, we divided it by $m_{\mathrm{b}}^{0.75}$, since RWL scales allometrically with MR (Schmidt-Nielsen, 1970).

We estimated the surface area of bats using the following morphometric measurements from 4 to 7 individuals of each species: length of the body, length of the tail, width of the body, length of the forearm, 
length of the third digit, and width and length of the ear. With these measurements we calculated total surface area as the sum of the surface area of the wing, the ears, the uropatagium and the body. We correlated total surface area with body mass of individuals, for each species, and we used the allometric coefficients generated from this correlation to estimate total surface area for each bat used in our study.

We used ANCOVA to test for significant differences in surface specific (ss) TEWL, metabolic rate corrected (ms) RWL and ssCEWL, using TRi as a covariate, and $T_{\mathrm{a}}$ and species as fixed factors. Finally, to evaluate if there were differences at which CEWL and RWL decreased with depth of torpor, we regressed CEWL vs RWL, using TRi as a covariate, separately for each bat species.

All statistical analyses were done with $\mathrm{R}$, version 3.1.2., using the 'nlme' package, and SPSS 22. Data are reported as means \pm SD and we chose $\alpha$ of 0.05 to reject our null hypotheses. We log-transformed data when they were heteroscedastic.

To compare values of TEWL in this study with those of other species, we collected TEWL data from the literature and calculated allometric equations for 35 species of bat (see Table 1 ). Species were designated as mesic $(n=21)$ or desert $(n=14)$, based on habitat description by the authors. We collected TEWL data for bats within their thermal-neutral zones (TNZ), which ranged from $\sim 20$ to $39.5^{\circ} \mathrm{C}$, and did a phylogenetic signal k-test (Blomberg et al., 2003) on the values of TEWL and $m_{\mathrm{b}}$ for all species. For these analyses, we used a macro for Microsoft Office Excel 2007 (by P. C. Withers, School of Animal Biology, University of Western Australia) to calculate the expected values and predicted 95\% confidence intervals for each variable. Since the phylogenetic signal was not significant $\left(k_{m \mathrm{~b}}=0.18, P=\right.$ $0.17, k_{\text {TEWL }}=0.06, P=0.41$ ), we did not make phylogenetic corrections. We used ANCOVA to compare TEWL between mesic and desert species, with $m_{\mathrm{b}}$ as a covariate and "habitat" (mesic vs. desert) as a factor. First, we evaluated a full model with the interaction " $m_{\mathrm{b}}$ " $\times$ "habitat" to test for significant differences in the slopes between $m_{\mathrm{b}}$ and TEWL. Since the slopes were not significantly different, we removed the interaction term from the analysis and tested for significant differences in the intercepts.

\section{Results}

The average values of all the variables measured in each bat species in this study are presented in Table 1 .

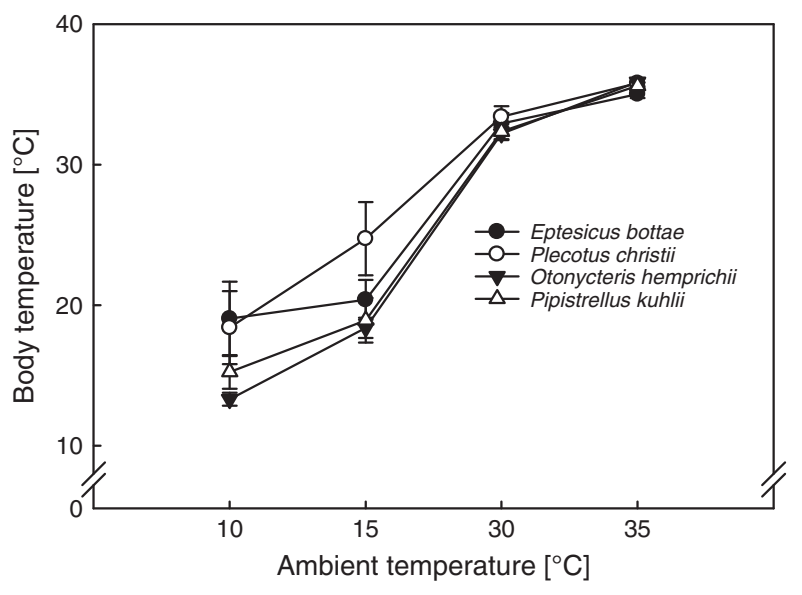

Fig. 1. The relationship between body temperature $\left(T_{\mathrm{b}}\right)$ and ambient temperature $\left(T_{\mathrm{a}}\right)$ in Eptesicus bottae, Otonycteris hemprichii, Plecotus christii and Pipistrellus kuhlii. Values are means $\pm \mathrm{SD}$. Body temperature decreased with $T_{\mathrm{a}}$, but there were no significant differences among species.

\subsection{Body temperature}

Body temperature increased significantly with $T_{\mathrm{a}}$ in all species $\left(T_{\mathrm{a}}\right.$ : $F_{1,75}=368.97, P<0.001$, Fig. 1$)$. $P$. christii had higher $T_{\mathrm{b}}$ than 0 . hemprichii $(P=0.04)$ and $P$. kuhlii $(P=0.005)$ at all values of $T_{\mathrm{a}}$ (Fig. 1 ; Species: $F_{3,75}=4.28, P<0.01$ ), but the $T_{\mathrm{b}}$ of $P$. christii did not differ significantly from that of $E$. bottae $(P=0.2)$.

\subsection{Metabolic rate and thermoregulatory index}

We found a significant interaction of " $T_{\mathrm{a}}$ " by "species" for MR $\left(F_{9,95}=2.90, P=0.004\right.$, Fig. 2$)$. We suggest that this result can be explained by the fact that there was large variability in MR in all species of bats, probably because individuals experienced different levels of torpor during measurements. Therefore, to control for differences in thermoregulatory states, we calculated TRi for all bats and incorporated this variable in our analyses. We found that $\mathrm{TR}_{\mathrm{i}}$ decreased significantly with $T_{\mathrm{a}}$ in all species, indicating that torpor was deeper at low $T_{\mathrm{a}}$ (Fig. 3; $T_{\mathrm{a}}: F_{3,105}=91.9, P<0.001$ ). We also found differences among

Table 1

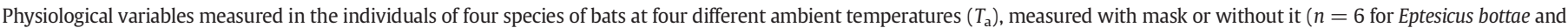

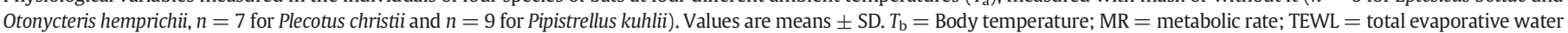
loss; $\mathrm{RWL}=$ respiratory water loss; $\mathrm{CEWL}=$ cutaneous evaporative water loss.

\begin{tabular}{|c|c|c|c|c|c|c|c|c|c|}
\hline \multirow[t]{2}{*}{$T_{\mathrm{a}}\left({ }^{\circ} \mathrm{C}\right)$} & \multirow[t]{2}{*}{ Species } & \multicolumn{2}{|l|}{$T_{\mathrm{b}}\left({ }^{\circ} \mathrm{C}\right)$} & \multicolumn{2}{|l|}{$\mathrm{MR}(\mathrm{mW})$} & \multicolumn{2}{|l|}{ TEWL $(\mathrm{g} / \mathrm{h})$} & \multirow{2}{*}{$\begin{array}{l}\text { RWL } \\
(\mathrm{g} / \mathrm{h})\end{array}$} & \multirow{2}{*}{$\begin{array}{l}\text { CEWL } \\
(\mathrm{g} / \mathrm{h})\end{array}$} \\
\hline & & No mask & Mask & No mask & Mask & No mask & Mask & & \\
\hline \multirow[t]{4}{*}{10} & E. bottae & $19.03 \pm 6.5$ & $17.25 \pm 5.1$ & $27.96 \pm 35.89$ & $63.37 \pm 88.48$ & $0.24 \pm 0.12$ & $0.53 \pm 0.15$ & $0.21 \pm 0.08$ & $0.32 \pm 0.12$ \\
\hline & P. christii & $19.65 \pm 6.6$ & $16.1 \pm 1.4$ & $32.41 \pm 57.07$ & $35.45 \pm 54.54$ & $0.29 \pm 0.15$ & $0.58 \pm 0.22$ & $0.19 \pm 0.1$ & $0.39 \pm 0.2$ \\
\hline & O. hemprichii & $13.3 \pm 1.1$ & $26.78 \pm 1.3$ & $29.27 \pm 19.18$ & $776.23 \pm 106.05$ & $0.56 \pm 0.16$ & $1.58 \pm 0.35$ & $0.6 \pm 0.2$ & $0.98 \pm 0.22$ \\
\hline & P. kuhlii & $15.24 \pm 3.6$ & $15.94 \pm 2.1$ & $22.85 \pm 31.04$ & $52.33 \pm 53.23$ & $0.26 \pm 0.19$ & $0.59 \pm 0.17$ & $0.23 \pm 0.11$ & $0.36 \pm 0.08$ \\
\hline \multirow[t]{4}{*}{15} & E. bottae & $20.38 \pm 3.5$ & $25.7 \pm 5.1$ & $19.45 \pm 14.79$ & $309.65 \pm 260.21$ & $0.45 \pm 0.27$ & $0.81 \pm 0.18$ & $0.39 \pm 0.25$ & $0.41 \pm 0.22$ \\
\hline & P. christii & $24.01 \pm 7.2$ & $23.3 \pm 4.3$ & $61.02 \pm 71.67$ & $138.06 \pm 137.78$ & $0.35 \pm 0.11$ & $0.73 \pm 0.17$ & $0.31 \pm 0.06$ & $0.42 \pm 0.12$ \\
\hline & O. hemprichii & $18.38 \pm 1.7$ & $28.55 \pm 2.4$ & $24.13 \pm 23.93$ & $648.21 \pm 84.13$ & $0.42 \pm 0.09$ & $1.69 \pm 0.36$ & $0.72 \pm 0.21$ & $0.97 \pm 0.24$ \\
\hline & P. kuhlii & $18.9 \pm 4.7$ & $19.2 \pm 3.5$ & $25.3 \pm 37.09$ & $68.6 \pm 95.98$ & $0.28 \pm 0.2$ & $0.81 \pm 0.39$ & $0.38 \pm 0.22$ & $0.43 \pm 0.19$ \\
\hline \multirow[t]{4}{*}{30} & E. bottae & $32.93 \pm 1.8$ & $32.15 \pm 1.3$ & $91.18 \pm 48.36$ & $113.69 \pm 96.58$ & $1.26 \pm 0.7$ & $1.22 \pm 0.53$ & $0.5 \pm 0.38$ & $0.71 \pm 0.49$ \\
\hline & P. christii & $33.26 \pm 2.1$ & $32.9 \pm 2.1$ & $46.26 \pm 27.54$ & $63.11 \pm 34.99$ & $0.5 \pm 0.1$ & $0.96 \pm 0.19$ & $0.44 \pm 0.18$ & $0.52 \pm 0.19$ \\
\hline & O. hemprichii & $32.21 \pm 1.1$ & $33 \pm 0.6$ & $117.64 \pm 39.8$ & $151.43 \pm 32.56$ & $0.86 \pm 0.25$ & $2.36 \pm 0.29$ & $1.16 \pm 0.09$ & $1.19 \pm 0.23$ \\
\hline & P. kuhlii & $32.36 \pm 1.6$ & $31.7 \pm 1$ & $34.49 \pm 15.24$ & $55.64 \pm 35.31$ & $0.41 \pm 0.12$ & $1 \pm 0.22$ & $0.47 \pm 0.13$ & $0.53 \pm 0.16$ \\
\hline \multirow[t]{4}{*}{35} & E. bottae & $35.03 \pm 0.6$ & $35.2 \pm 1$ & $60.19 \pm 28.17$ & $85.36 \pm 44.91$ & $1.06 \pm 0.25$ & $1.95 \pm 0.73$ & $0.99 \pm 0.6$ & $0.96 \pm 0.17$ \\
\hline & P. christii & $36.06 \pm 0.5$ & $35.65 \pm 1.1$ & $68.58 \pm 31.59$ & $70.14 \pm 36.05$ & $1.53 \pm 0.68$ & $1.44 \pm 0.65$ & $0.68 \pm 0.37$ & $0.77 \pm 0.28$ \\
\hline & O. hemprichii & $35.88 \pm 0.7$ & $36.16 \pm 0.7$ & $115.41 \pm 51.28$ & $135.76 \pm 19.56$ & $1.67 \pm 0.43$ & $2.57 \pm 0.33$ & $1.32 \pm 0.32$ & $1.25 \pm 0.27$ \\
\hline & P. kuhlii & $35.62 \pm 0.6$ & $34.77 \pm 1.2$ & $41.88 \pm 5.42$ & $48.94 \pm 17.08$ & $0.54 \pm 0.16$ & $1.28 \pm 0.17$ & $0.73 \pm 0.11$ & $0.55 \pm 0.12$ \\
\hline
\end{tabular}




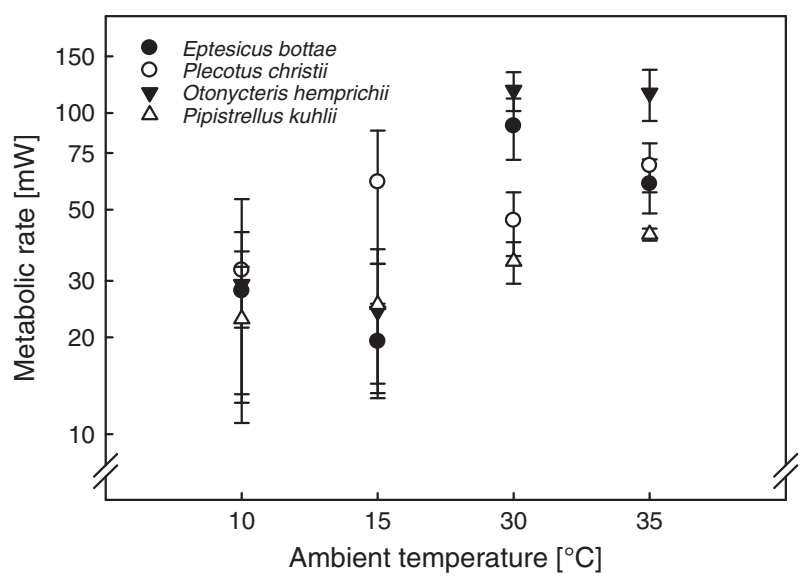

Fig. 2. The relationship between metabolic rate (MR) and ambient temperature $\left(T_{\mathrm{a}}\right)$ in Eptesicus bottae, Otonycteris hemprichii, Plecotus christii and Pipistrellus kuhlii. Values are means $\pm \mathrm{SD}$. There was high variability in MR at all $T_{\mathrm{a}} \mathrm{S}$, probably because bats experienced different levels of torpor.

species, $O$. hemprichii having significantly lower TRi than the other species $\left(F_{3,105}=3.87, P<0.02\right)$, Thus, individual 0 . hemprichii entered shallower torpor than the other bat species.

\subsection{Total evaporative water loss}

We found high variability in surface-specific TEWL (ssTEWL) among species and at different $T_{\mathrm{a}}$, probably because bats were at different torpor depths (Fig. 4B). To account for these differences, we included TRi as a covariate in our analyses, and found that TRi covaried significantly with ssTEWL (Fig. 4A; $F_{1,103}=110.3, P<0.001$ ), namely it is apparent that as torpor depth increased, ssTEWL decreased (Fig. 4A). We found that, for bats, at the same depth of torpor, ssTEWL was significantly lower at low $T_{\mathrm{a}}\left(10\right.$ and $\left.15{ }^{\circ} \mathrm{C}\right)$ than at higher $T_{\mathrm{a}}\left(30\right.$ and $\left.35{ }^{\circ} \mathrm{C}\right)$ (Fig. 4A; $T_{\mathrm{a}}: F_{3,103}=10.73, P<0.01$ ). Comparing among species, and after correction for torpor depth, ssTEWL of $O$. hemprichii was lower than that of the other species of bats (Fig. $4 \mathrm{~A}$; Species: $F_{3,103}=40.74$, $P<0.001)$.

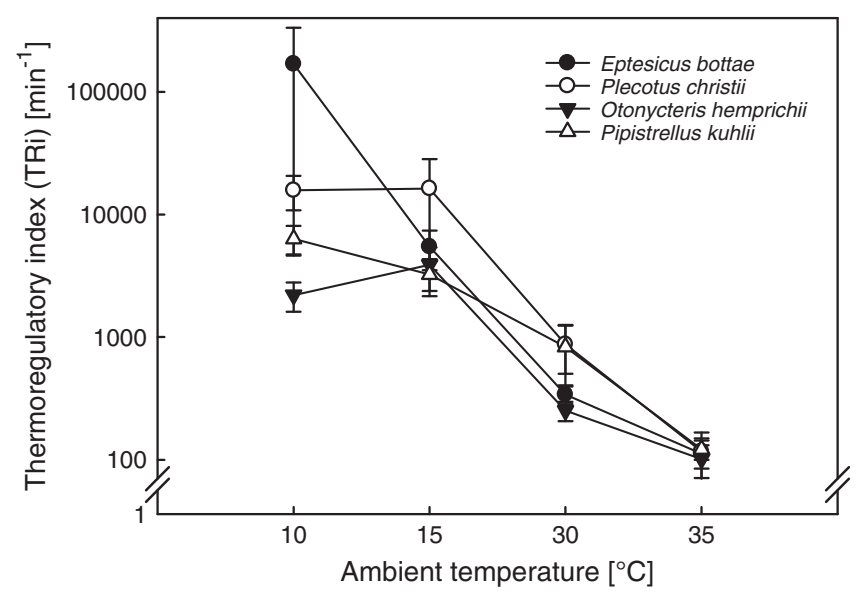

Fig. 3. The relationship between the thermoregulatory index (TRi) and ambient temperature $\left(T_{\mathrm{a}}\right)$ in Eptesicus bottae, Otonycteris hemprichii, Plecotus christii and Pipistrellus kuhlii. Values are means $\pm \mathrm{SD}$. The $\mathrm{TR}_{\mathrm{i}}$ decreased with $T_{\mathrm{a}}$, indicating that bats entered deeper torpor at low $T_{\mathrm{a}}$ O O. hemprichii had a significantly lower TRi than that of the other species of bats.
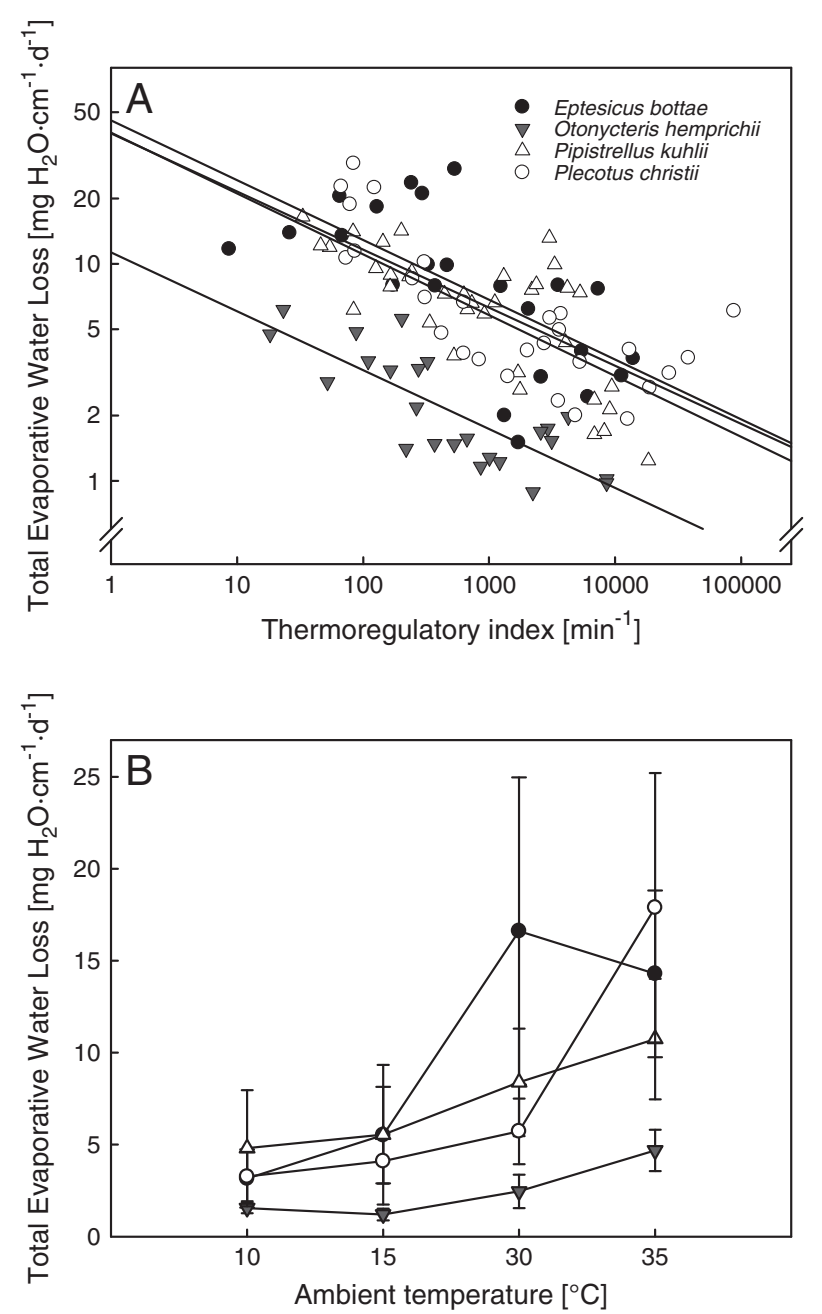

Fig. 4. (A) The relationship between surface-specific total evaporative water loss (ssTEWL) and the thermoregulatory index (TRi) in Eptesicus bottae, Otonycteris hemprichii, Plecotus christii and Pipistrellus kuhlii. As torpor depth increased, ssTEWL decreased in all species. 0 . hemprichii had significantly lower ssTEWL than the other species, after accounting for differences in the thermoregulatory state of individuals. (B) The relationship between ssTEWL and ambient temperature $\left(T_{\mathrm{a}}\right)$ in E. bottae, O. hemprichii, P. christii and P. kuhlii. Values are means $\pm \mathrm{SD}$.

To compare TEWL of the four species we studied with TEWL of other species of bats from different environments, we collected data for TEWL from the literature, and divided the species into those that live in the desert $(n=14)$ and those that live in mesic environments $(n=21$, Table 2, Fig. 5). We used only data from normothermic bats, in their TNZs. ANCOVA of TEWL for all the species, with $m_{\mathrm{b}}$ as a covariate, did not indicate a significant interaction term between habitat and $m_{\mathrm{b}}$ $(P=0.68)$; therefore, the slope of the relationship between TEWL and $m_{\mathrm{b}}$ was the same for species living in different habitats. After removing the interaction term, we found that habitat (desert or mesic) was significant $(F=22.7, P<0.001)$, indicating that the y-axis intercept of the regression line relating TEWL and $m_{\mathrm{b}}$ was significantly different between desert and mesic species. The estimated rate of TEWL for a desert species with a body mass of $10 \mathrm{~g}$ was $40.86 \mathrm{mg}$ water/h, whereas for mesic species, the calculated TEWL for a 10 -g bat was $61.88 \mathrm{mg}$ water/h, indicating that TEWL in desert bats is lower than that of mesic bats. The four species used in the present study had the lowest TEWL among all of the species of bats for which we have data (Fig. 5). 
Table 2

Body mass $\left(m_{\mathrm{b}}\right)$, total evaporative water loss (TEWL) during normothermy, taxonomic affiliation and habitat of 35 species of bats.

\begin{tabular}{|c|c|c|c|c|c|}
\hline Species & $m_{\mathrm{b}}(\mathrm{g})$ & TEWL $(\mathrm{g} / \mathrm{h})$ & Family & Habitat & Reference (original) \\
\hline Macroderma gigas & 107.20 & 0.227 & Megadermatidae & Mesic & Baudinette et al., 2000 \\
\hline Rhinonycteris aurantius & 8.27 & 0.092 & Hipposideridae & Mesic & Baudinette et al., 2000 \\
\hline Natalus stramineus & 5.59 & 0.071 & Natalidae & Mesic & Studier, 1970 \\
\hline Noctilio albiventris & 39.90 & 0.110 & Noctilionidae & Mesic & Roverud and Chappell, 1991 \\
\hline Taphozous mauritanicus & 26.2 & 0.031 & Emballonuridae & Desert & Toussaint and McKechnie, 2012 \\
\hline Nycteris thebaica & 11.7 & 0.055 & Nycteridae & Desert & Toussaint and McKechnie, 2012 \\
\hline Macrotus californicus & 11.70 & 0.086 & Phyllostomidae & Desert & Bell et al., 1986 \\
\hline Leptonycteris curasoae & 22.00 & 0.175 & Phyllostomidae & Desert & Carpenter and Graham, 1967 \\
\hline Leptonycteris sanborni & 22.00 & 0.090 & Phyllostomidae & Mesic & Carpenter and Graham, 1967 \\
\hline Glossophaga soricina & 11.31 & 0.112 & Phyllostomidae & Desert & Studier, 1970 \\
\hline Artibeus hirsutus & 48.00 & 0.178 & Phyllostomidae & Mesic & Carpenter and Graham, 1967 \\
\hline Tadarida brasiliensis & 16.90 & 0.038 & Molossidae & Desert & Herreid and Schmidt-Nielsen, 1966 \\
\hline Tadarida teniotis & 31.97 & 0.028 & Molossidae & Desert & Marom et al., 2006 \\
\hline Molossus coibensis & 14.71 & 0.080 & Molossidae & Mesic & Studier, 1970 \\
\hline Mops condylurus & 23.24 & 0.037 & Molossidae & Desert & Maloney et al., 1999 \\
\hline Sauromys petrophilus & 11.0 & 0.012 & Molossidae & Desert & Toussaint and McKechnie, 2012 \\
\hline Miniopterus schreibersii & 10.91 & 0.063 & Vespertilionidae & Mesic & Baudinette et al., 2000 \\
\hline Chalinobolus gouldii & 17.50 & 0.032 & Vespertilionidae & Mesic & Hosken and Withers, 1997 \\
\hline Lasiurus cinereus & 32.50 & 0.183 & Vespertilionidae & Desert & Cryan and Wolf, 2003 \\
\hline Nyctophilus geoffroyi & 8.00 & 0.020 & Vespertilionidae & Mesic & Hosken and Withers., 1999 \\
\hline Nyctophilus gouldi & 8.00 & 0.011 & Vespertilionidae & Mesic & Morris et al., 1994 \\
\hline Nyctophilus major & 13.60 & 0.036 & Vespertilionidae & Mesic & Hosken, 1997 \\
\hline Plecotus auritus & 9.12 & 0.113 & Vespertilionidae & Mesic & Webb, 1995 \\
\hline Pipistrellus pipistrellus & 6.20 & 0.084 & Vespertilionidae & Mesic & Webb, 1995 \\
\hline Myotis lucifugus & 9.00 & 0.073 & Vespertilionidae & Desert & Procter and Studier, 1970 \\
\hline Myotis daubentonii & 10.00 & 0.066 & Vespertilionidae & Mesic & Webb, 1995 \\
\hline Myotis nigricans & 4.02 & 0.047 & Vespertilionidae & Mesic & Studier, 1970 \\
\hline Myotis nattereri & 8.70 & 0.036 & Vespertilionidae & Mesic & Willis et al., 2011 \\
\hline Myotis velifer & 9.70 & 0.033 & Vespertilionidae & Mesic & Studier et al., 1970 \\
\hline Myotis yumanensis & 5.00 & 0.044 & Vespertilionidae & Mesic & Licht and Leitner, 1967 \\
\hline Myotis thysanoides & 8.00 & 0.066 & Vespertilionidae & Mesic & Studier et al., 1970 \\
\hline Plecotus christii & 6.8 & 0.003 & Vespertilionidae & Desert & This study \\
\hline Pipistrellus kuhlii & 6.8 & 0.003 & Vespertilionidae & Desert & This study \\
\hline Eptesicus bottae & 8.95 & 0.006 & Vespertilionidae & Desert & This study \\
\hline Otonycteris hemprichii & 29.71 & 0.001 & Vespertilionidae & Desert & This study \\
\hline
\end{tabular}

\subsection{Respiratory and cutaneous water loss}

Total evaporative water loss, the sum of CEWL and RWL, in bats wearing a mask to separate CEWL from RWL, was significantly higher than TEWL of the same individuals measured mask-free for all species (paired $t$-test, $t_{109}=13.6, P<0.001$ ), a difference that we ascribe to stress (see Muñoz-Garcia et al., 2012a). The purpose of fitting the bats with a mask was to calculate separately the respiratory and cutaneous components of TEWL. For bats wearing a mask, and using TRi as a covariate, we found the same patterns between TEWL and $T_{\mathrm{a}}$ and species as

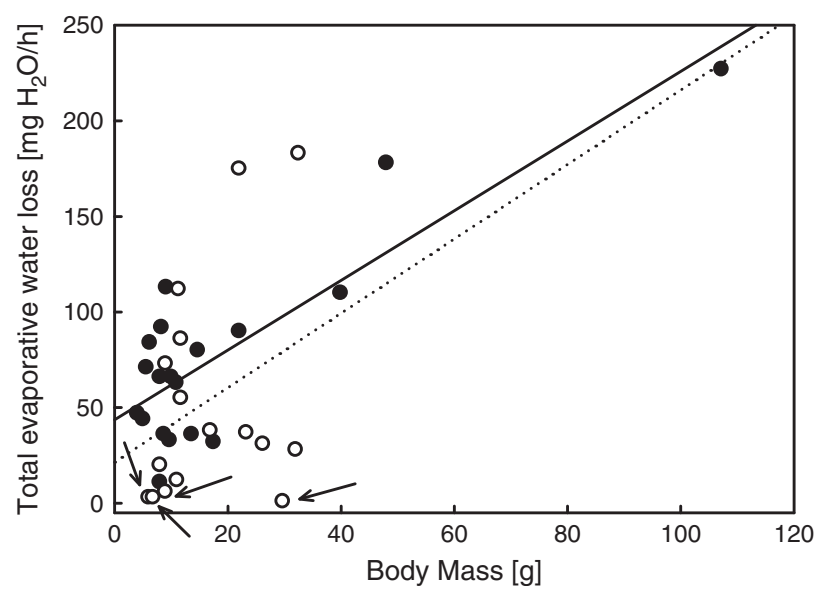

Fig. 5. Relationship between total evaporative water loss (TEWL) and body mass $\left(m_{\mathrm{b}}\right)$ in mesic species (filled symbols and solid line; TEWL $=43.66+1.82 m_{\mathrm{b}}, \mathrm{R}^{2}=0.71$; $P<0.001$ ) and desert species (unfilled symbols and dashed line; TEWL $=21.46+1.94$ $m_{\mathrm{b}}, \mathrm{R}^{2}=0.10 ; P=0.23$ ). TEWL was significantly lower in desert species than in mesic species after accounting for $m_{\mathrm{b}}$. Arrows indicate the species that were measured in this study.

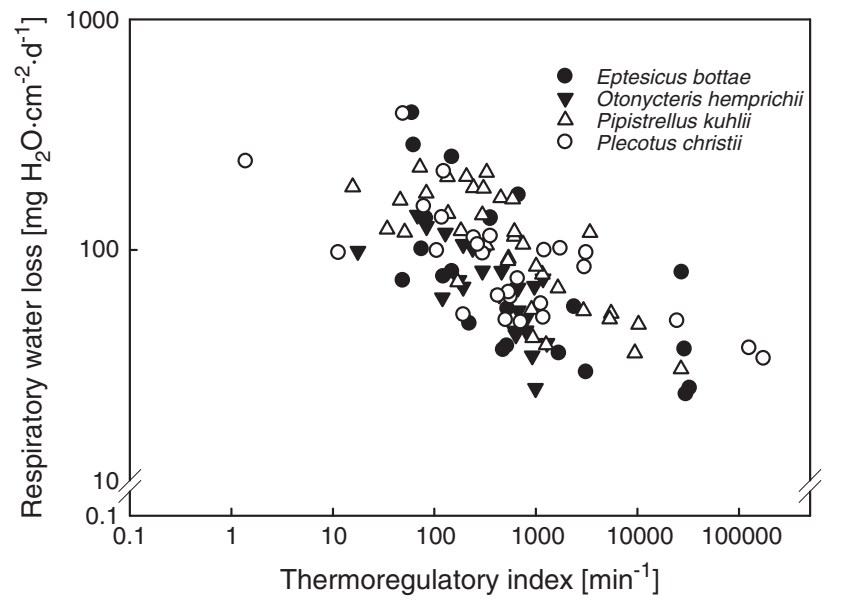

Fig. 6. The relationship between surface-specific respiratory water loss (ssRWL) and the thermoregulatory index (TRi) in Eptesicus bottae, Otonycteris hemprichii, Plecotus christii and Pipistrellus kuhlii. As torpor depth increased, ssRWL decreased in all species. $O$. hemprichii had significantly lower ssRWL than the other species, $P$. christii and $E$. bottae had intermediate values for ssRWL, and $P$. kuhlii had a significantly higher ssRWL than the other three species, after accounting for differences in the thermoregulatory state of individuals. 


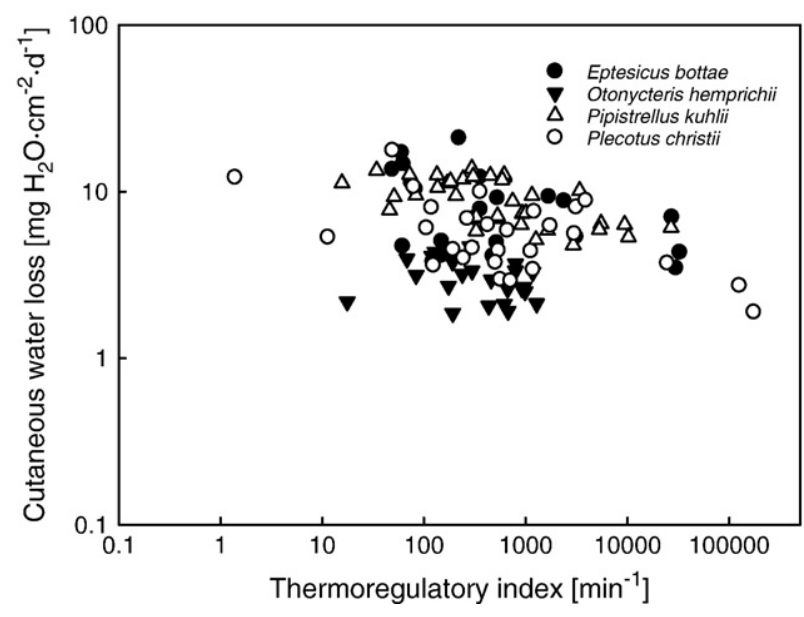

Fig. 7. The relationship between surface-specific cutaneous evaporative water loss (sSCEWL) and the thermoregulatory index (TRi) in Eptesicus bottae, Otonycteris hemprichii, Plecotus christii and Pipistrellus kuhlii. As torpor depth increased, CEWL decreased in all species, except in $O$. hemprichii, where it remained constant. $O$. hemprichii had a significantly lower sSCEWL than the other species, after accounting for differences in the thermoregulatory state of individuals.

for bats measured without a mask, i.e., TEWL of bats measured with the mask decreased significantly with $T_{\mathrm{a}}\left(F_{3,102}=9.96, P<0.001\right)$, and TEWL differed significantly among species $\left(F_{3,102}=55.7, P<0.001\right)$, with $O$. hemprichii having the lowest TEWL and $P$. kuhlii having the largest TEWL. Taking this into account, and since all individuals were subjected to the same experimental conditions, we consider our results of RWL and CEWL comparable among species.

Since bats measured wearing a mask were at different torpor depths, we corrected for this variable using TRi as a covariate. We found that TRi was a significant covariate for metabolism-specific $\mathrm{RWL}\left[\mathrm{msRWL}=\mathrm{RWL} /\left(m_{\mathrm{b}}^{0.75}\right)\right]$ (Fig. $\left.6 \mathrm{~A} ; F_{1,102}=45.2, P<0.001\right)$, indicating that msRWL decreased as depth of torpor increased. After correcting for depth of torpor, msRWL increased significantly with $T_{\mathrm{a}}$ $\left(F_{3,102}=8.70, P<0.001\right)$. We also found significant differences in msRWL among species; for bats at the same torpor depth, $O$. hemprichii had the lowest msRWL, P. christii and E. bottae had intermediate rates of msRWL, and $P$. kuhlii had the highest msRWL (Fig. 6; $\left.F_{3,102}=2.91, P<0.04\right)$.

We found that TRi covaried significantly with $\operatorname{ssCEWL}\left(F_{1,102}=24.2\right.$, $P<0.001$ ), suggesting that ssCEWL decreased as depth of torpor increased. For bats at the same depth of torpor, ssCEWL increased significantly with $T_{\mathrm{a}}\left(F_{3,102}=4.63, P<0.005\right)$. We also found significant differences in ssCEWL among species; for bats at the same torpor depth, $O$. hemprichii had the lowest ssCEWL, P. christii had intermediate SSCEWL, and E. bottae and P. kuhlii had the highest SsCEWL (Fig. 7; $F_{3,102}=48.1, P<0.001$ ).

Using ANCOVA with TRi as a covariate, we regressed CEWL on RWL and found significant interactions for $O$. hemprichii and P. kuhlii, indicating that the slopes of these relationships were significantly different $(P<0.04)$, i.e., CEWL and RWL did not decrease at the same rate with TRi in these species (Fig. 8). In P. christii and E. bottae, CEWL was significantly higher than RWL at the same torpor depth $(P<0.04)$, but the slopes of these relationships were not significantly different $(P>0.21$; Fig. 8).

\section{Discussion}

Contrary to our predictions, but in agreement with Marom et al. (2006), P. kuhlii the only widespread species that we studied, did not have significantly higher MR than the semi-desert species. However, there was high individual variation in MR in all four species, particularly $E$. bottae and P. christii. This high variability in MR was due to the fact that some bats entered torpor during measurements, whereas others remained normothermic. Therefore, to compare the physiological variables of interest, we chose to calculate TRi, a continuous variable that estimates the thermoregulatory state of an heterothermic endotherm (Muñoz-Garcia et al., 2014). We found that TRi was correlated with $T_{\mathrm{a}}$, indicating that, as expected, depth of torpor increased as $T_{\mathrm{a}}$ decreased. When we compared TRi among species, we found that TRi of O. hemprichii was significantly higher than that of the other species, suggesting that 0 . hemprichii used shallower torpor at low temperatures than the others.

The minimum TRi of 0 . hemprichii was calculated for $T_{\mathrm{a}}=15^{\circ} \mathrm{C}$, whereas for the other species minimum TRi was calculated for $T_{\mathrm{a}}=$ $10{ }^{\circ} \mathrm{C}$. Moreover, TRi for 0 . hemprichii at $15^{\circ} \mathrm{C}$ was similar to TRi of the other species at $10^{\circ} \mathrm{C}$, indicating that 0 . hemprichii reached the same depth of torpor at $15^{\circ} \mathrm{C}$ as the other species did at $10^{\circ} \mathrm{C}$. It is possible that the minimum preferred temperature $\left(T_{\mathrm{pm}}\right)$, the value of $T_{\mathrm{a}}$ at which torpor metabolic rate is lowest, is higher in desert species than in mesic species. As a "true" desert species, 0 . hemprichii probably does not experience low $T_{\mathrm{a}} \mathrm{s}$ most of the year and, from an evolutionary perspective, we think that it is reasonable to assume that $10^{\circ} \mathrm{C}$ is below the $T_{\mathrm{pm}}$ for this species. Taken together, these results suggest that, at low $T_{\mathrm{a}}$, bats use torpor as an energy and water loss saving mechanism (Speakman and Thomas, 2003; Geiser, 2004). It seems, however, that 0 . hemprichii has a relatively high $T_{\mathrm{pm}}$, perhaps an adaptation to hot, arid environments.

Surface-specific TEWL (ssTEWL) decreased with depth of torpor in all species, as we predicted. After correction for torpor depth (as indicated by TRi), rates of ssTEWL in 0 . hemprichii were significantly lower, but SsTEWL of $P$. kuhlii was not significantly higher, than those of the other species, a result that partially supports our predictions. Desert populations of the widespread $P$. kuhlii have similar rates of ssTEWL as those of other desert-dwelling species, perhaps because of genetic differences among populations that live in different environments, or because of acclimatization to desert environments, ideas that need to be tested. In house sparrows (Passer domesticus), Muñoz-Garcia et al. (2008) found that acclimatization accounted for most of the variation observed in CEWL between desert and mesic populations. Similar results were obtained for Merriam's kangaroo rat, Dipodomys merriami (Tracy and Walsberg, 2001). However, it seems that TEWL in laboratory rats, Rattus norvegicus, shows a major genetic component (Furuyama and Ohara, 1993).

To further explore the association of TEWL with habitat, we collected data for other species of bats from the literature. We found evidence that rates of TEWL might be lower in desert than in mesic species (see also Maloney et al., 1999; Toussaint and McKechnie, 2012). All the species we examined in this study had significantly lower rates of TEWL than predicted by the allometric equation that we generated. This might be due to methodological differences between studies; for example, in some studies TEWL was measured gravimetrically, whereas in others rates of TEWL were estimated using open-flow respirometry. There might also be unaccounted-for differences in the torpor depth of bats. We chose species measured within at thermoneutrality, but slight differences in the depth of torpor might alter rates of TEWL.

In all species in this study, except 0 . hemprichii, both SSCEWL and msRWL decreased with depth of torpor, as we predicted. Interestingly, in O. hemprichii ssCEWL did not change with TRi. P. kuhlii had the highest rates of msRWL and SsCEWL of all the four species, after accounting for torpor depth. 0 . hemprichii had significantly lower ssRWL and ssCEWL than the other species, at the same TRi. Both $P$. christii and E. bottae showed intermediate values for SSRWL and SsCEWL. These results support our hypothesis that SSCEWL and msRWL are negatively correlated with aridity of the habitat of the studied species. 
In considering the relationship between RWL and CEWL with $\mathrm{TR}_{\mathrm{i}}$ for each species, interesting patterns emerged. Respiratory water loss decreased with TRi at the same rate in all species, i.e., the slopes of the relationships between RWL and TRi were the same for all species $(P>0.05$, ANCOVA with TRi as a covariate). This suggests that the decrease in RWL is a by-product of the decrease in MR concomitant with torpor. In P. christii and E. bottae, RWL and CEWL decreased at the same rate with increasing TRi. However, we found that CEWL decreased with TRi at a slower rate than RWL in P. kuhlii. Supporting these results, Muñoz-Garcia et al. (2012a) studied the relationship between CEWL and torpor depth in P. kuhlii and, based on their results, hypothesized that during deep torpor, animals do not efficiently regulate CEWL. The authors concluded that CEWL in P. Kuhlii increased with torpor depth, even though they used the gradient between $T_{\mathrm{b}}$ and $T_{\mathrm{a}}\left(T_{\mathrm{b}}-T_{\mathrm{a}}\right)$ as a proxy for depth of torpor. The use of $T_{\mathrm{b}}-T_{\mathrm{a}}$ as a measure of the thermoregulatory state of a bat is problematic, since thermoneutral bats might have the same score as bats in deep torpor (Muñoz-Garcia et al., 2014). We did not find CEWL to increase with depth of torpor in P. kuhlii, rather it decreased. However, CEWL decreased at a slower rate than RWL during deep torpor, reinforcing the hypothesis that during deep torpor, regulation of CEWL is somehow impaired. We also found a significant interaction term between CEWL and RWL in O. hemprichii. In this case, RWL decreased with TRi, but CEWL remained constant with TRi, suggesting that CEWL in
O. hemprichii is mainly determined by a structural component, that is probably independent of body temperature.

One of the main determinants of the rates of CEWL in endotherms is the lipid composition of the stratum corneum (SC), the outer layer of the epidermis (Williams and Tieleman, 2005; Lillywhite, 2006; Muñoz-Garcia et al., 2008). Lipids in the SC are arranged in layers and organized in an ordered fashion which prevents excessive passage of water vapor across the skin (Muñoz-Garcia et al., 2008). The function of the skin as a barrier to evaporation depends on the composition and organization of the lipids of the SC, a structural component, and a regulatory component, including enzyme activity, changes in the $\mathrm{pH}$ within layers of the SC, vasoconstriction and vasodilation (see Elias, 2004), which together determine the permeability of the barrier under different environmental conditions. During deep torpor, the structural components of the permeability barrier are unlikely to change substantially, but the regulatory, active mechanisms that increase resistance to water vapor diffusion across the skin are probably less effective, since they require energy expenditure for proper functioning. The fact that CEWL did not change significantly with depth of torpor in 0 . hemprichii, suggests that the structural component of the permeability barrier is more important than the regulatory components in this species. It is possible that the composition and organization of the lipids of the SC in 0 . hemprichii are such that results in low rates of CEWL at high values of $T_{a}$, at the cost of low flexibility when
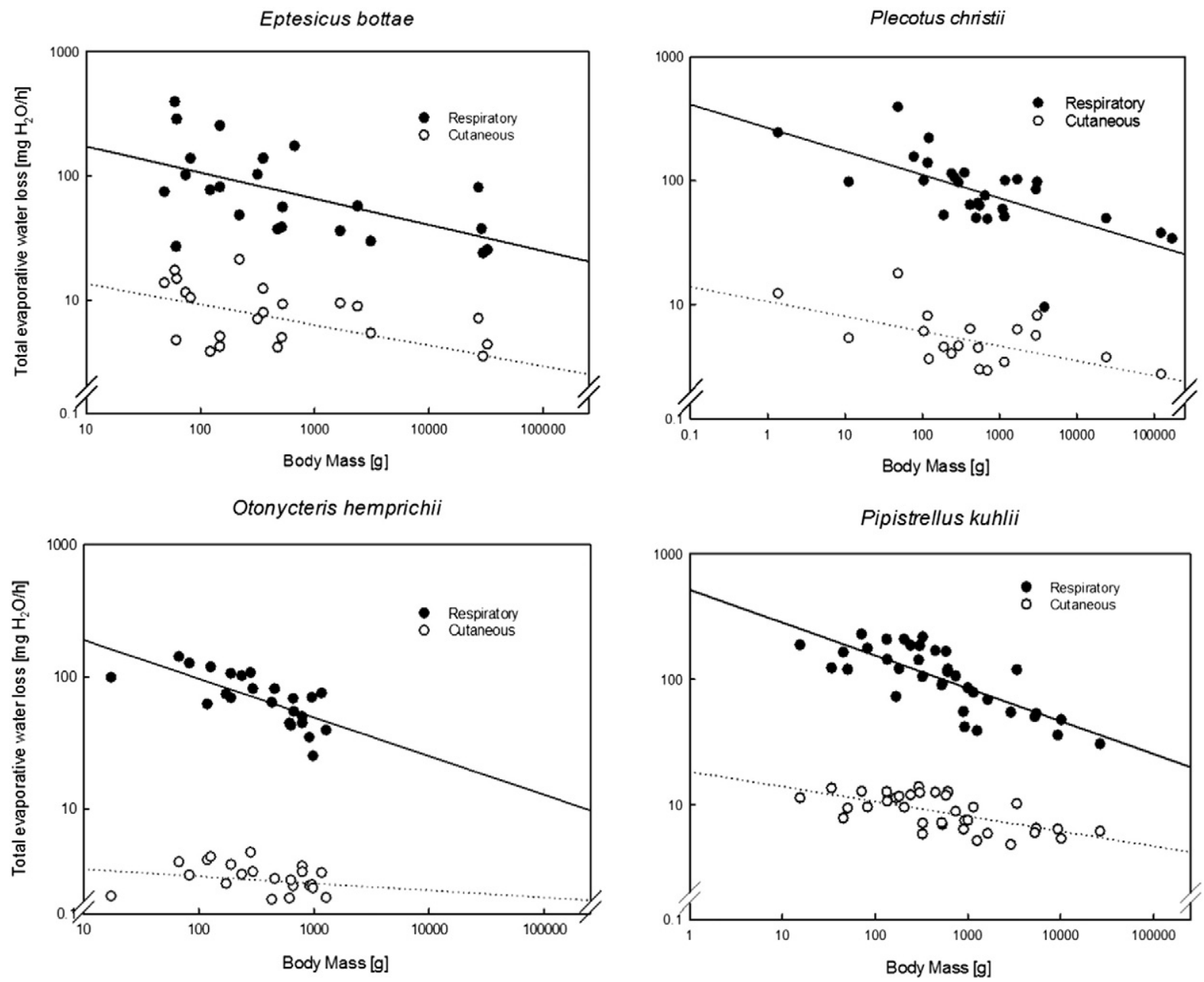

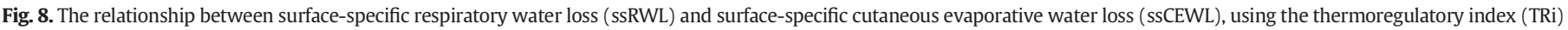

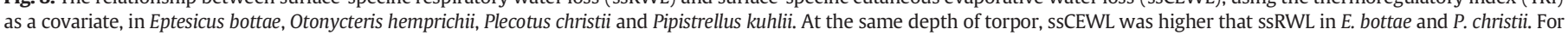
$O$. hemprichii and $P$. kuhlii we found a significant interaction term, indicating that ssRWL and ssCEWL did not decrease with depth of torpor at the same rate. 
$T_{\mathrm{a}} \mathrm{s}$ drop and individuals are torpid. Further studies are needed to explore this idea.

To conclude, we hypothesized that bats living in desert environments would be physiologically adapted to minimize energy expenditure and water loss. We predicted that MR and evaporative water loss would therefore be lower in desert species than in mesic species. Our results are not sufficient to make an unequivocal statement that desert-dwelling bats do have lower MR, but they indicate that they have lower rates of TEWL, RWL and CEWL than those of mesic species. We also hypothesized that evaporative water loss would decrease with torpor depth in bats. As predicted, we observed a significant reduction in RWL and CEWL with torpor depth.

\section{Acknowledgments}

This research was supported by grant number 2008469 of the USIsrael Binational National Science Foundation to CK and JBW, and a Blaustein Postdoctoral Fellowship and a VATAT fellowship from the Council of Higher Education, awarded to AM-G. APCN was supported by a travel grant from The Graduate Program of the State University of São Paulo (PROPG - UNESP) and by a research grant from FAPESP (\#08/57687-0). This research was done under permit 37066 to Carmi Korine from the Israel Nature and Parks Authority and under permit IL-71-12-2010 from the Ben-Gurion University committee for the ethical care and use of animals in experiments. We thank two anonymous reviewers for useful comments in the preparation of the last version of this manuscript. This is paper number 884 of the Mitrani Department of Desert Ecology.

\section{References}

Baudinette, R.V., Churchill, S.K., Christian, K.A., Nelson, J.E., Hudson, P.J., 2000. Energy, water balance and the roost microenvironment in three Australian cave-dwelling bats (microchiroptera). J. Comp. Physiol. B. 170, 439-446.

Bell, G.P., Bartholomew, G.A., Nagy, K.A., 1986. The roles of energetics, water economy, foraging behavior, and geothermal refugia in the distribution of the bat, Macrotus californicus. J. Comp. Physiol. B. 156, 441-450.

Ben-Hamo, M., Munoz-Garcia, A., Williams, J.B., Korine, C., Pinshow, B., 2013. Waking to drink: rates of evaporative water loss determine arousal frequency in hibernating bats. J. Exp. Biol. 216, 573-577.

Blomberg, S.P., Garland, T., Ives, A.R., 2003. Testing for phylogenetic signal in comparative data: behavioral traits are more labile. Evolution 57, 717-745.

Bozinovic, F., Marquet, P.A., 1991. Energetics and torpor in the Atacama desert-dwelling rodent Phyllotis darwinirupestris. J. Mammal. 72, 734-738.

Brack, V., Twente, J.W., 1985. The duration of the period of hibernation of three species of vespertilionid bats. I. Field studies. Can. J. Zool. 65, 1240-1242.

Carpenter, R.E., 1969. Structure and function of the kidney and water balance of desert bats. Physiol. Zool. 42, 288-302.

Carpenter, R.E., Graham, J.B., 1967. Physiological responses to temperature in the longnosed bat, Leptonycteris sanborni. Comp. Biochem. Physiol. 22, 709-722.

Cryan, P.M., Wolf, B.O., 2003. Sex differences in the thermoregulation and evaporative water loss of a heterothermic bat, Lasiurus cinereus, during its spring migration. J. Exp. Biol. 206, 3381-3390.

Elias, P.M., 2004. The epidermal permeability barrier: from the early days at Harvard to emerging concepts. J. Invest. Dermatol. 122, 36-39.

Fenton, M.B., Simmons, N.B., 2014. Bats: A World of Science and Mystery. University of Chicago Press, Chicago.

Furuyama, F., Ohara, K., 1993. Genetic development of an inbred rat strain with increased resistance adaptation to a hot environment. Am. J. Physiol. 265, R957-R962.

Geiser, F., 2004. Metabolic rate reduction during hibernation and daily torpor. Biol. Pap. Univ. Alaska 27, 175-184.

Hart, J.S., 1951. Calorimetric determination of average body temperature of small mammals and its variation with environmental conditions. Can. J. Zool. 29, 224-233.

Herreid, C.F., Schmidt-Nielsen, K., 1966. Oxygen consumption, temperature and water loss in bats from different environments. Am. J. Physiol. 211, 108-1112.

Hill, J.E., Smith, J.D., 1984. Bats: A Natural History. University of Texas Press, Austin.

Hosken, D.J., 1997. Thermal biology and metabolism of the greater long-eared bat, Nyctophilus major (Chiroptera: Vespertilionidae). Aust. J. Zool. 45, 145-156.

Hosken, D.J., Withers, P.C., 1997. Temperature regulation and metabolism of an Australian bat, Chalinolobus gouldii (Chiroptera: Vespertilionidae) when euthermic and torpid. J. Comp. Physiol. B. 167, 71-80.

Hosken, D.J., Withers, P.C., 1999. Metabolic physiology of euthermic and torpid lesser long-eared bats, Nyctophilus geoffroyi (Chiroptera: Vespertilionidae). J. Mammal. 80, 42-52.

Korine, C., Pinshow, B., 2004. Guild structure, foraging space use, and distribution in a community of insectivorous bats in the Negev desert. J. Zool. 262, 187-196.
Kunz, T.H., 1982. Ecology of Bats. Plenum Press, New York.

Licht, P., Leitner, P., 1967. Physiological responses to high environmental temperatures in three species of microchiropteran bats. Comp. Biochem. Physiol. 22, 371-387.

Lillywhite, H.B., 2006. Water relations of tetrapod integument. J. Exp. Biol. 209, 202-226.

Lovegrove, B.G., 2000. The zoogeography of mammalian basal metabolic rate. Am. Nat. $156,201-219$.

Lovegrove, B.G., 2003. The influence of climate on the basal metabolic rate of small mammals: a slow-fast metabolic continuum. J. Comp. Physiol. B. 173, 87-112.

Lovegrove, B.G., Raman, J., 1998. Torpor patterns in the pouched mouse (Saccostomus campestris; Rodentia): a model animal for unpredictable environments. J. Comp. Physiol. B. 168, 303-312.

Maloney, S.K., Bronner, G.N., Buffenstein, R., 1999. Thermoregulation in the Angolan freetailed bat Mops condylurus: a small mammal that uses hot roosts. Physiol. Biochem. Zool. 72, 385-396.

Marom, S., Korine, C., Wojciechowski, M.S., Tracy, C.R., Pinshow, B., 2006. Energy metabolism and evaporative water loss in the European free-tailed bat and Hemprich's long-eared bat (Microchiroptera): species sympatric in the Negev desert. Physiol. Biochem. Zool. 79, 944-956.

McNab, B.K., 1982. Ecology of Bats. Evolutionary Alternatives on the Physiological Ecology of Bats. Plenum Publishing Corp, New York.

Minnaar, I.A., Bennett, N.C., Chimimba, C.T., McKechnie, A.E., 2014. Partitioning of evaporative water loss into respiratory and cutaneous pathways in Wahlberg's Epauletted fruit bats (Epomophorus wahlbergi). Physiol. Biochem. Zool. 87 $475-485$.

Morris, S., Curtin, A.L., Thompson, M.B., 1994. Heterothermy, torpor, respiratory gas exchange, water balance and the effect of feeding in Gould's long-eared bat Nyctophilus gouldi. J. Exp. Biol. 197, 309-335.

Muñoz-Garcia, A., Ro, J., Brown, B.J.C., Williams, J.B., 2008. Cutaneous water loss and sphingolipids in the stratum corneum of house sparrows, Passer domesticus L. from desert and mesic environments as determined by reversed phase highperformance liquid chromatography coupled with atmospheric pressure photospray ionization mass spectrometry. J. Exp. Biol. 211, 447-458.

Muñoz-Garcia, A., Ben-Hamo, M., Pinshow, B., Williams, J.B., Korine, C., 2012a. The relationship between cutaneous water loss and thermoregulatory state in Kuhl's pipistrelle Pipistrellus kuhlii, a Vespertillionid bat. Physiol. Biochem. Zool. 85, 516-525.

Muñoz-Garcia, A., Ro, J., Reichard, J.D., Kunz, T.H., Williams, J.B., 2012b. Cutaneous water loss and lipids of the stratum corneum in two syntopic species of bats. Comp. Biochem. Physiol. A 61, 208-215.

Muñoz-Garcia, A., Ben-Hamo, M., Korine, C., Pinshow, B., Williams, J.B., 2014. A new thermoregulatory index for heterothermy. Methods Ecol. Evol. 5, 141-145.

Nowak, R.M., 1999. Walker's Mammals of the World. John Hopkins University Press, Baltimore.

Noy-Meir, I., 1973. Desert ecosystems: environment and producers. Annu. Rev. Ecol. Syst. 4, 25-51.

Procter, J.W., Studier, E.H., 1970. Effects of ambient temperature and water vapor pressure on evaporative water loss in Myotis lucifugus. J. Mammal. 51, 799-804.

Rambaldini, D.A., Brigham, R.M., 2008. Torpor use by free-ranging pallid bats (Antrozous pallidus) at the northern extent of their range. J. Mammal. 89, 933-941.

Roverud, R.C., Chappell, M.A., 1991. Energetic and thermoregulatory aspects of clustering behavior in the neotropical bat Noctilio albiventris. Physiol. Zool. 64, 1527-1541.

Ruf, T., Geiser, F., 2014. Daily torpor and hibernation in birds and mammals. Biol. Rev. http://dx.doi.org/10.1111/brv.12137.

Schmidt-Nielsen, K., 1964. Desert Animals. Oxford University Press, London.

Schmidt-Nielsen, K., 1970. Energy metabolism, body size, and problems of scaling. Fed. Proc. 29, 1524-1532.

Schmidt-Nielsen, K., 1997. Animal Physiology: Adaptation and Environment. Cambridge University Press.

Schmidt-Nielsen, B., Schmidt-Nielsen, K., 1950. Evaporative water loss in desert rodents in their natural habitat. Ecology 31, 75-85.

Speakman, J.R., Thomas, D.W., 2003. Physiological ecology and energetics of bats. In: Kunz, T.H., Fenton, M.B. (Eds.), Bat Biology. University of Chicago Press, Chicago IL.

Studier, E.H., 1970. Evaporative water loss in bats. Comp. Biochem. Physiol. 35, 935-943.

Studier, E.H., Procter, J.W., Howell, D.J., 1970. Diurnal body weight loss and tolerance of weight loss in five species of Myotis. J. Mammal. 51, 302-309.

Thomas, S.P., Follette, D.B., Farabaugh, A.T., 1991. Influence of air-temperature on ventilation rates and thermoregulation of a flying bat. Am. J. Physiol. 260 R960-R968.

Tieleman, B.I., Williams, J.B., 2002. Cutaneous and respiratory water loss in larks from arid and mesic environments. Physiol. Biochem. Zool. 75, 590-599.

Toussaint, D.C., McKechnie, A.E., 2012. Interspecific variation in thermoregulation among three sympatric bats inhabiting a hot, semi-arid environment. J. Comp. Physiol. B. $182,1129-1140$

Tracy, R.L., Walsberg, G.E., 2001. Developmental and acclimatory contributions to water loss in a desert rodent: investigating the time course of adaptive change. J. Comp. Physiol. B 171, 669-679.

Turbill, C., Law, B.S., Geisera, F., 2003. Summer torpor in a free-ranging bat from subtropical Australia. J. Therm. Biol. 28, 223-226.

Van Sant, M.J., Oufiero, C.E., Munoz-Garcia, A., Hammond, K.A., Williams, J.B., 2012. A phylogenetic approach to total evaporative water loss in mammals. Physiol. Biochem. Zool. 85, 526-532.

Webb, P.I., 1995. The comparative ecophysiology of water balance in microchiropteran bats. Symp. Zool. Soc. Lond. 67, 203-218. 
Williams, J.B., Tieleman, B.I., 2005. Physiological adaptation in desert birds. Bioscience 55 416-425.

Willis, C.K.R., Menzies, A.K., Boyles, J.G., Wojciechowski, M.S., 2011. Evaporative water loss is a plausible explanation for mortality of bats from white-nose syndrome. Integr. Comp. Biol. 51, 364-373.

Withers, P.C., 1977. Measurement of Vo2, Vco2, and evaporative water-loss with a flowthrough mask. J. Appl. Physiol. 42, 120-123.
Yom-Tov, Y., Kadmon, R., 1998. Analysis of the distribution of insectivorous bats in Israel. Divers. Distrib. 4, 63-70.

Zubaid, A., McCracken, G.F., Kunz, T.H., 2006. Functional and Evolutionary Ecology of Bats. Oxford University Press, New York. 